\title{
ФИЗКУЛЬТУРНОЕ ОБРАЗОВАНИЕ В АСПЕКТЕ НОВОЙ ОБРАЗОВАТЕЛЬНОЙ ПАРАДИГМЫ
}

\section{PHYSICAL EDUCATION IN THE ASPECT OF THE NEW EDUCATIONAL PARADIGM}

A. Barybin
A. Vasilyev

Summary: The article considers the validity of introducing the concept of physical education as a higher level of physical culture development in its multi-functional and multi-component nature, as well as the issues of the influence of physical education on the worldview, spiritual and moral spheres of life of young people.

Keywords: physical education, physical culture, professional mobility, sport, teacher of physical education, physical training, motor skills.
Барыбин Алексей Валентинович

К.п.н., доцент, Егорьевский технологический институт (филиал) ФГБОУ ВО МГТУ «СТАНКИН» barybinav60@gmail.com

Васильев Алексей Георгиевич

Старший преподаватель, Егорьевский технологический институт (филиал) ФГБОУ ВО МГТУ «СТАНКИН»

alex_vas@ro.ru

Аннотация: В статье рассматривается правомерность введения понятия физического образования как более высокого уровня освоения физической культуры в ее многофункциональности и многокомпонентности, а также вопросы влияния физического образования на мировоззрение, духовную и нравственную сферы жизни молодежи.

Ключевые слова: физкультурное образование, физическая культура, профессиональная мобильность, спорт, преподаватель физической культуры, физическая подготовка, двигательные умения.

плину, нужную и важную для каждого отдельно взятого индивида и общества в целом?

Отвечая на этот вопрос, хотелось бы обратиться к проведенному опросу преподавателей физической культуры технических вузов и аргументированно высказать мысль о том, что большинство преподавателей (52\%) выражают готовность к постоянному совершенствованию методических знаний и освоению новых квалификаций, в особенности квалификации «преподаватель-тренер»; $21 \%$ (что, что, на наш взгляд, не мало) были бы согласны обновлять свои знания в области теории физической культуры, изучить новые методы преподавания дисциплины, но не видят перспектив их внедрения в педагогическую практику, так как недостаточно удовлетворены постановкой физкультурного образования в вузе; 28\% преподавателей высказались за необходимость улучшения управленческой и методической поддержки и сопровождения инициатив преподавателей физической культуры в техническом вузе.

Проведенный опрос позволил нам сделать вывод о том, что развитие профессиональной мобильности преподавателей физической культуры тесным образом связано с переосмыслением потенциала самой дисциплины, повышении ее статуса и значимости в кругу других дисциплин. Одним из условий, на наш взгляд, является переход от узкоспециализированного понятия физической культуры к понятию физкультурного образования, воплощающему в себе и физическую культуру, и обучение/преподавание физической культуры (формы, методы, технологии, включая информационно-коммуникаци- 
онные) и современные программы профессиональной переподготовки специалистов.

Следуя логике исследования, остановимся на рассмотрении понятия физкультурного образования в аспекте новой образовательной парадигмы для того, чтобы определить направления и организационно-педагогические условия развития профессиональной мобильности преподавателя физической культуры в области физкультурного образования.

Начало исследованию феномена физкультурного образования положено известным ученым П.Ф. Лесгафтом [4]. Согласно его научной концепции, физкультурное образование является осознанным процессом воздействия физических упражнений на человека для формирования двигательных умений и навыков, как способность контролировать, анализировать, строить двигательные действия, как содействие развитию разумного человека. И, несмотря на то что в концепции, разработанной ученым, заложены идеи о гуманистической, образовательной и культурологической сущности физкультурного образования, по своему содержанию она может быть отнесена к концепциям физического образования. И многие из его идей, как заметил профессор В.П. Лукьяненко [5], не нашли в практике своего применения.

Это связано с тем, что в педагогической практике дисциплина физической культуры понималась как обучение физическим упражнениям для укрепления здоровья, воспитания волевых качеств, развитие интереса к спорту через вовлечение в спортивные секции. Но время поставило перед новым поколением новые задачи, связанные с оздоровлением общества, развитием олимпийского движения, воспитанием гражданских качеств через занятия спортом, что является важным для укрепления и безопасности государства. Необходимость решения этих задач привело к необходимости исследовать многофункциональность и многокомпонентность учебной дисциплины физической культуры и обосновать введение понятия физкультурного образования, раскрыв его образовательные, воспитательные и социокультурные ценности в соответствии с новым образовательным стандартом.

В научной литературе понятие физкультурного образования широко исследовано многими учеными (Н.А. Карпушко, В.В. Приходько, А.Ю. Славина, А.Б. Смирнов, И.И. Сулейманов и др.). Исследователи полагают, что физкультурное образование является более высоким уровнем освоения физической культуры, который характеризует физкультурно-образованную личность. Такая личность легко включается в физкультурно-спортивную деятельность вуза, проявляет активность и самостоятельно занимается спортом. Следует полагать, что образование в области физической культуры, ста- новится частью культуры современного общества и призвано готовить студенческую молодежь не только к физической (двигательной) и спортивной деятельности, но и к социокультурной. Социокультурная деятельность требует от студентов владения умениями использовать свои физические, интеллектуальные и коммуникативные способности в коллективе; участвовать в спортивных мероприятиях организации, общественных собраниях, проявлять инициативу и творчество в решении профессиональных проблем.

О правомерности использования понятия физкультурного образования в педагогической практике пишут А.В. Залевский и Н.Н. Епифанова [3]. Исследователи также утверждают, что физкультурное образование направлено не только на развитие физических способностей, морфофункциональных возможностей организма и двигательных навыков, но и на формирование мировоззрения, системы ценностей, мотивационной сферы личности, широты знаний в области физической культуры.

По мнению Ю.М. Николаева [6], актуальным вопросом в научной области знаний является создание культуросообразной теории, которая позволила бы раскрыть ценностный потенциал физкультурного образования и его влияния на мировоззрение, духовную и нравственную сферы жизни молодежи. Культуросообразная теория отражает новый взгляд на содержание физкультурного образования и раскрывает его функции в современном интерактивном обществе, позволяет лучше понять отличие физической культуры от физического воспитания, где внимание сосредоточено на телесно-двигательной стороне личности студента, то есть на его физической подготовке.

Отдавая предпочтение культурологическому подходу в физкультурном образовании, многие ученые, такие, как В.К. Бальсевич, А.П. Матвеев, Ю.М. Николаев, Н.И. Пономарев, В.И. Столяров и др., считают, что названный подход отражает суть физкультурного образования, которая состоит в том, что физическая культура, как его важнейший компонент, проникает в другие виды культур (нравственная, духовная, досуговая и др.) и происходит их взаимодействие, взаимодополняемость. В этом случае, ее содержательные характеристики должны обосновываться, исходя из философского понимания культуры, а основной методологической позицией следует считать гармонию физического (телесного) и духовного (социального), достигаемую одухотворением физического. Это, как заметили А.В. Залевский и Н.Н. Епифанова [3], обусловлено сущностью культуры, соотношением биологического, телесного и духовного в человеке, генезисом знания о физической культуре. Физическая культура как феномен общей культуры уникальна. По словам В.К. Бальсевича, она соединяет социальное и биологическое в развитии человека [1]. Помимо этого, как полагает 
Н.Н. Визитей [2], она является базовым видом культуры. Физическая культура оказывает существенное влияние на состояние организма, психики, статус человека. Как известно из научных источников, физическая культура формировалась, прежде всего, под влиянием практических потребностей общества в полноценной физической подготовке подрастающего поколения и взрослого населения к труду. Однако по мере становления системы физкультурного образования физическая культура становилась базовым фактором формирования двигательных умений и навыков. Более глубокое переосмысление ценности физической культуры позволило заявить о ее сильном влиянии на духовную сферу личности.

Эффективность физкультурного образования обеспечивается междисциплинарной интеграций, преемственностью обучения, воспитания и развития личности студента на каждом этапе и уровне образования, начиная с раннего детства. Этот процесс включает формирование особых интеллектуальных способностей личности: к рефлексии, креативному мышлению, сознательному восприятию реальности для самооценки своего здоровья, физического и морального состояния. Результатом обучения должно быть создание устойчивой мотивации и потребности к здоровому и продуктивному стилю жизни, физическому самосовершенствованию, достижению максимального уровня физической подготовленности.

Профессиональная направленность образовательного процесса по физической культуре включается во все разделы рабочей программы вуза, выполняя связующую, координирующую и активизирующую роль. Эффективность реализации образовательной программы зависит от уровня квалификации и компетентности преподавателя физической культуры.

\section{ЛИТЕРАТУРА}

1. Бальсевич В.К., Лубышева Л.И. От физического воспитания к созданию отечественной системы спортивного образования в школе // Евразийский форум.- 2009.- № 1.- С-153-168.

2. Визитей Н.Н. Физическая культура личности: (Пробл. человеч. телесности: методол., социал.-филос., пед. аспекты) / Н.Н. Визитей; ОтВ. ред. В.И. Столяров; Кишин. гос. пед. ин-т им. И. Крянгэ. - Кишинев: Штиинца, 1989. - 107 с.

3. Залевский Н.Н., Епифанова А.В. От физического воспитания к физкультурному образованию и физкультурному воспитанию. -Образование в современном мире. Сборник научных статей. -Саратов: Институт дополнительного профессионального образования Саратовского национального исследовательского государственного университета, под ред. проф. Ю.Г. Голуба, 2016.- (-14-20

4. Лесгафт П.Ф. Руководство по физическому образованию детей школьного возраста // Лесгафт П.Ф. Избранные труды / Сост. И.Н.Решетень. - М.: ФиС, 1987.-359c.

5. Лукьяненко В.П. Концепция модернизации системы общего среднего физкультурного образования в России. / В.П. Лукьяненко. - М.: Советский спорт, $2007-120 \mathrm{c}$.

6. Николаев Ю.М. Теория физической культуры: становление и развитие культурологического подхода / Ю.М. Николаев // Теория и практика физ. культуры. $-2009 .-$ № 12. - C. 3-8.

7. Федеральный закон «0 физической культуре и спорте в Российской Федерации» от 29.04.1999 г. № 80-Ф3 (в ред. Федеральных законов от 10.01 .2003 г. № 15-Ф3, от 20.12.2004 г. № 167-Ф3). 